\title{
The Effects of Recombinant Human Granulocyte- Macrophage Colony Stimulating Factor on in Vitro Cord Blood Granulocyte Function
}

\author{
ROBERT W. FRENCK, JR, E. STEPHEN BUESCHER, AND SAROJ VADHAN-RAJ \\ Program in Infectious Diseases and Clinical Microbiology, University of Texas Medical School at Houston \\ [R.W.F., E.S.B.] and Department of Clinical Immunology and Biological Therapy, M.D. Anderson Hospital, \\ Houston, Texas [S.V-R.]
}

\begin{abstract}
Neonatal granulocytes are recognized to have functional defects which are thought to be important in the increased susceptibility to infection in the neonate. Recombinant human granulocyte-macrophage colony-stimulating factor (rhGM-CSF), a member of a family of glycoproteins essential for the in vitro survival, proliferation, and differentiation of hematopoeitic progenitor cells, has been shown to enhance the functional capabilities of adult granulocytes. This study tested the effects of rhGMCSF on the locomotion, superoxide generation, phagocytosis, bactericidal activity, and membrane depolarization responses of cord blood granulocytes. Concentrations of rhGM-CSF between 100 and $1 \mathrm{pM}$ significantly enhanced the leading front of cord blood granulocyte locomotion. The mean distance migrated by the cell population and the number of cells responding to the chemoattractant were also significantly enhanced in cord blood granulocytes treated with $1 \mathrm{pM}$ rhGM-CSF. Superoxide anion production was significantly enhanced in cord blood granulocytes stimulated with fMLP after a 30- or 60-min exposure to $100 \mathrm{pM}$ rhGM-CSF. However, this enhancing effect was not observed in cells incubated with rhGM-CSF for $2 \mathrm{~h}$ before formyl-methionine-leucine-phenylalanine stimulation. Phagocytosis, bactericidal activity, and membrane depolarization responses of cord blood granulocytes were not affected by exposure to rhGM-CSF. These findings demonstrate that selected cord blood granulocyte functions are enhanced by in vitro exposure to rhGM-CSF. Whether these in vitro observations have in vivo significance await further study. (Pediatr Res 26: 43-48, 1989)
\end{abstract}

\section{Abbreviations}

rhGM-CSF, recombinant human granulocyte-macrophage colony stimulating factor

HBSS, Hank's Balanced Salt Solution

fMLP, Formyl-methionine-leucine-phenylalanine

AcS, zymosan-activated serum

$A+f$, zymosan-activated serum plus fMLP

CSF are glycoproteins essential for the in vitro survival, proliferation and differentiation of hematopoeitic progenitor cells (1, 2). One of these, GM-CSF has multilineage proliferation effects

Received July 18, 1988; accepted March 23, 1989.

Supported through NICHHD Grant HD 13021-09

Correspondence Robert W. Frenck, Jr., M.D., Pediatric Infectious Diseases, University of Texas Medical School at Houston, 6431 Fannin Street, Room 1.739, Houston, TX 77030 in vitro, stimulating granulocyte, macrophage, eosinophil, megakaryocyte, and erythroid colony growth.

Recently the gene for hGM-CSF has been cloned $(1,3)$ allowing biosynthetic production of a recombinant product. For the first time, large quantities of pure GM-CSF are available, making it possible to more thoroughly study and characterize this glycoprotein. As a result, it is now appreciated that in addition to its proliferative effects, GM-CSF has functional effects on mature granulocytes. It increases phagocytosis $(4,5)$, enhances fMLPstimulated superoxide production (6), causes lysozyme secretion (4), alters membrane depolarization responses (7), alters adhesion (8), and is itself a weak granulocyte chemoattractant (10). GMCSF has also been identified as the neutrophil migration inhibition factor from $T$ cells (NIF-T) (9), a lymphokine that suppresses granulocyte migration.

Despite evaluation of the effects of GM-CSF on granulocytes obtained from adults, little information exists on the effects of this protein on neonatal granulocytes. Since neonatal granulocytes are widely recognized to be functionally less competent than adult cells (11-19) and because GM-CSF enhances certain adult granulocyte functions, we hypothesized that GM-CSF might also enhance neonatal granulocyte functions. We therefore performed the following studies to examine the effects of in vitro GM-CSF exposure on umbilical cord blood granulocyte function.

\section{MATERIALS AND METHODS}

Isolation of granulocytes. Heparinized $(1 \mathrm{U} / \mathrm{ml})$ umbilical cord blood was collected after birth by venipuncture of the umbilical cord of healthy, term infants. Paired samples of heparinized blood were obtained from healthy adult volunteers as controls. Granulocytes were purified by Hypaque (Winthrop Breon Lab, NY)-Ficoll (Sigma Chemical Co., St. Louis, MO) gradient centrifugation (20), followed by $3 \%$ dextran (Sigma) sedimentation and hypotonic lysis. The resulting cells were washed and resuspended in HBSS without $\mathrm{Ca}^{++}$or $\mathrm{Mg}^{++}$(HBSS without).

$r h G M-C S F$. rhGM-CSF was prepared and provided by Immunex Corp (Seattle, WA). hGM-CSF cDNA was isolated from a library constructed of mRNA from the human $\mathrm{T}$ cell line HUT -102 inserted into and expressed in yeast (21). The purified rhGM-CSF has a specific activity of approximately $5 \times 10^{7}$ colony-forming $\mathrm{U} / \mathrm{mg}$ of protein (22). Its mol wt was assumed to be $22 \mathrm{kD}$. A stock GM-CSF solution was prepared by dissolving the lyophilized GM-CSF in normal saline at a concentration of $4.54 \mathrm{M}$. Aliquots of stock were kept frozen at $-70^{\circ} \mathrm{C}$ until used. Endotoxin contamination was $<1 \mathrm{ng} / \mathrm{mg}$ of lyophilized GM-CSF as measured by the Limulus amebocyte lysate assay.

Granulocyte locomotion. Locomotion was measured using a 
modified under-agarose assay (23). One part Eagle's minimal essential medium $(2 \times$ concentration) was combined with one part agarose $\left(0.24 \mathrm{~g} / 10 \mathrm{ml} \mathrm{H}_{2} \mathrm{O}\right)$ containing $10 \%$ autologous serum. rhGM-CSF in appropriate concentrations was added to the agarose mixture (creating a uniform concentration of rhGMCSF throughout the agarose) and 5-ml aliquots of agarose were placed into quadruplicate $60 \times 15 \mathrm{~mm}$ Petri dishes. Four pairs of parallel troughs were cut into each agarose plate, and $20 \mu 1$ of granulocytes (suspended in MEM and $10 \%$ autologous serum at $2.5 \times 10^{7} / \mathrm{ml}$ ) were placed in the inner trough, the locomotive stimulus was placed in the outer. The locomotive stimuli used were HBSS without, AcS, $5 \times 10^{-7} \mathrm{M}$ fMLP (Sigma) and activated serum plus fMLP $(\mathrm{A}+\mathrm{f})$. To evaluate the chemoattractant properties of rhGM-CSF, the locomotive stimuli AcS, fMLP, and $\mathrm{A}+\mathrm{f}$ were replaced by $10 \mathrm{nM}, 100 \mathrm{pM}$, and $1 \mathrm{pM}$ rhGMCSF in the outer trough of the agarose plate. The rhGM-CSF diffused into the agarose presenting the cell with a gradient of the glycoprotein. After $4 \mathrm{~h}$ of incubation at $37^{\circ} \mathrm{C}$, the plates were fixed for $5 \mathrm{~min}$ with formalin and the cells were stained with Diff-Quik (Scientific Products, McGaw Park, IL). Leading front distances were measured from projected images of the stained plates and quadruplicate measurements were averaged.

Image analysis of locomotion. Triplicate fixed, stained chemotaxis plates were scanned on a computerized, automated image analysis system that utilizes a high resolution video camera $(6 \mu$ / pixel) (24). The video camera scans an area 400 pixels wide by 400 pixels deep, starting at the edge of the cell trough and progressing toward the stimulus trough. The computer assigns a value from 1 to $256(1=$ white, $256=$ black $)$ to each pixel which corresponds to the cell density in that pixel. The density information in each 400 pixel wide swath is then averaged and plotted as a function of distance from the cell trough. Simultaneously, the leading front distance, the mean distance migrated by the cells, and the area under the curve (density $\times$ distance migrated) are measured and calculated.

Granulocyte superoxide production. Purified granulocytes $(2.5$ $\times 10^{6}$ cells $/ \mathrm{ml}$ ) were suspended in HBSS without, which contained $10 \%$ heat inactivated autologous serum and incubated at $37^{\circ} \mathrm{C}$ with either diluent or GM-CSF. At times $0,30,60,90$, and $120 \mathrm{~min}$, cord blood and adult granulocytes were aliquoted into three pairs of tubes $\left(1 \times 10^{6}\right.$ cells/tube). Superoxide dismutase (Sigma) $(0.025 \mathrm{mg} / \mathrm{ml}$ final concentrations) was added to one tube of each triplicate pair. fMLP was added to all of the tubes, followed by $0.1 \mathrm{ml}$ cytochrome c $(12.5 \mathrm{mg} / \mathrm{ml})$. The triplicate pairs of tubes were tumbled for 15 minutes at $37^{\circ} \mathrm{C}$ and then the cells were pelleted $(18,000 \times g, 30 \mathrm{~s})$ and discarded. The supernate was examined for reduced cytochrome $\mathrm{c}$ at $550 \mathrm{~nm}$ using a Gilford 25 spectrophotometer. The triplicate determinations were averaged and superoxide anion production per million cells per 15 min was then calculated using an extinction coefficient of $21(25)$.

Granulocyte membrane depolarization assay. Membrane depolarization responses were measured using the carbocyanine dye $\mathrm{DiOC}_{5}$ (3) (26). Purified granulocytes were suspended in HBSS without and incubated with rhGM-CSF or diluent at $37^{\circ} \mathrm{C}$. At times $0,30,60$, and $120 \mathrm{~min}$, aliquots of cells $\left(2.5 \times 10^{5}\right.$ cells/ml final concentration) were added to HBSS with $\mathrm{Ca}^{++}$and $\mathrm{Mg}^{++}$containing $2.5 \times 10^{-7} \mathrm{M} \mathrm{DiOC}_{5}$ (3) (Molecular Probes, Eugene, OR) for $5 \mathrm{~min}$ at $37^{\circ} \mathrm{C}$. After transfer to a cuvette, $2 \mathrm{ml}$ of cells were placed in a Perkin-Elmer fluorometer (Perkin-Elmer Corp., Norwalk, CT) with continuous stirring. After stabilization of the baseline, $20 \mu \mathrm{l}$ of fMLP stock were added and the reaction was allowed to continue for $5 \mathrm{~min}$ with continuous recording of fluorescence. Membrane depolarization responses are expressed as the percent decrease in fluorescence, calculated as $\Delta$ fluorescence/starting fluorescence.

Granulocyte phagocytosis assay. Purified granulocytes $(1 \times$ $10^{6}$ ) were suspended in $\mathrm{HBSS}$ with $\mathrm{Ca}^{++}$and $\mathrm{Mg}^{++}$containing $10 \%$ autologous serum and were incubated for $30 \mathrm{~min}$ at $37^{\circ} \mathrm{C}$ with either diluent or GM-CSF. Boiled Staphylococcus aureus (1 $\times 10^{8}$ ) were then added and the mixture was tumbled at $37^{\circ} \mathrm{C}$ for $30 \mathrm{~min}$. Aliquots of the mixture were removed at $5-\mathrm{min}$ intervals, and each was combined with $20 \mathrm{U}$ of lysostaphin (ICN, Cleveland, $\mathrm{OH}$ ) to remove extracellular bacteria (27). This mixture was incubated at $37^{\circ} \mathrm{C}$ for 30 min then placed on ice until cytocentrifuge slides were prepared. After staining (Diff-Quick), 200 granulocytes were counted, scoring each for the presence or absence of intracellular bacteria.

Granulocyte bacterial assay. Triplicate samples of purified granulocytes $\left(5 \times 10^{6}\right.$ final conc.) were suspended in $1 \mathrm{ml}$ of HBSS with $\mathrm{Ca}^{++}$and $\mathrm{Mg}^{++}$containing $10 \%$ autologous serum and either diluent or GM-CSF. Live $S$. aureus $\left(1 \times 10^{7}\right.$ organisms) were added and the mixture tumbled at $37^{\circ} \mathrm{C}$. Control mixtures, to determine $100 \%$ bacterial survival, were incubated without granulocytes and were plated at 10 minutes. Aliquots of the test mixtures were removed at 20,45 , and $90 \mathrm{~min}$ and lysed in sterile water. Samples of lysate were placed in $60 \times 15 \mathrm{~mm}$ Petri dishes and overlayed with warm trypticase-soy agar. Plates were incubated overnight at $37^{\circ} \mathrm{C}$, after which colonies of $S$. aureus were counted and bacterial survival was expressed as a percent of the control plate colony counts.

Statistical evaluation. Unless otherwise stated, all data shown are the mean \pm SEM of $(n)$ determinations and data are compared using either a two-tailed Student's $t$-test or a paired sample $t$-test (when natural pairing occurs) with $p<0.05$ taken as a significant difference.

\section{RESULTS}

Cell purification. Samples of cord blood yielded $5.75 \pm 0.51$ million purified cells per milliliter of blood $(n=50)$. Purified granulocyte fractions from cord blood contained $88 \pm 1.6$ percent granulocytes $(n=12)$. Adult control granulocyte preparations were typically $>90 \%$ pure.

Effects of GM-CSF on granulocyte locomotion. In vitro rhGM$\mathrm{CSF}$ exposure affected cord blood granulocyte locomotion in a dose-dependent fashion (Fig. 1). Significant suppression of chemotaxis toward $\mathrm{AcS}, \mathrm{fMLP}$, and $\mathrm{A}+\mathrm{f}$ resulted from exposure to $10 \mathrm{nM}$ GM-CSF ( $p<0.05 \mathrm{AcS}, p<0.01 \mathrm{fMLP}$ and $\mathrm{A}+\mathrm{f}$, paired sample $t$-test and Wilcoxon signed rank test) as compared to the same cells unexposed to rhGM-CSF. Cord blood granulocytes exposed to $1 \mathrm{pM}$ GM-CSF showed enhanced leading front distances compared to cord granulocytes not exposed to GM-CSF: AcS: $115 \pm 6 \%$ of unexposed $(p<0.025)$, fMLP: 119 $\pm 7 \%(p<0.01)$, and AcS + fMLP: $121 \pm 8 \%(p<0.01)$ (paired sample $t$-test and Wilcoxon signed rank test). Unstimulated locomotion (Fig. $1 A$ ) was significantly enhanced when cord blood granulocytes were exposed to $100 \mathrm{pM}$ rhGM-CSF ( $p<$ 0.02 , paired sample $t$-test and Wilcoxon signed rank test).

Three under-agarose chemotaxis experiments were performed testing rhGM-CSF as a chemoattractant. The total concentration of 100 pM rhGM-CSF acted as a weak but significant chemoattractant when compared to cells undergoing unstimulated locomotion toward HBSS $(108 \pm 2 \% 100$ pM rhGM-CSF stimulated cells/HBSS (unstimulated) cells, $p<0.05$ ). Chemotactic responsiveness to $10 \mathrm{nM}$ and $1 \mathrm{pM}$ rhGM-CSF was equivalent to unstimulated locomotion (106 \pm 4 and $102 \pm 1 \%$, respectively).

Three experiments were performed examining cord cell chemotaxis by image analysis. Cells exposed to $1 \mathrm{pM}$ rhGM-CSF then stimulated by fMLP increased their mean distance migrated and the area under the curve (number of granulocytes responding) to $155 \pm 7 \%(p<0.05)$ and $220 \pm 65 \%(p<0.05)$ of unexposed cell values, respectively. Granulocytes exposed to 1 pM rhGM-CSF then stimulated by activated serum or activated serum plus fMLP had an increased mean distance migrated by the population of cells and number of granulocytes responding 
A。

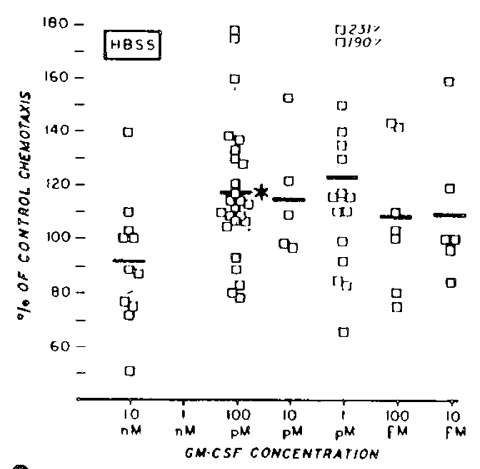

C。

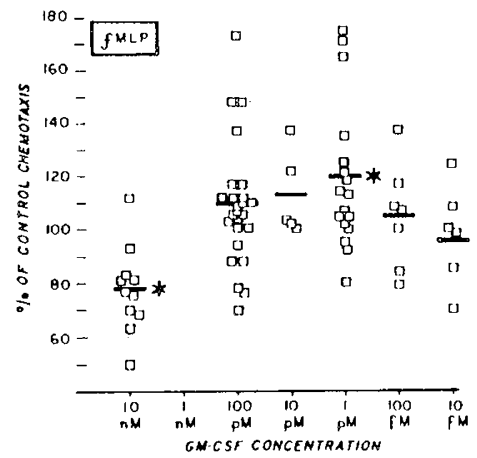

B.

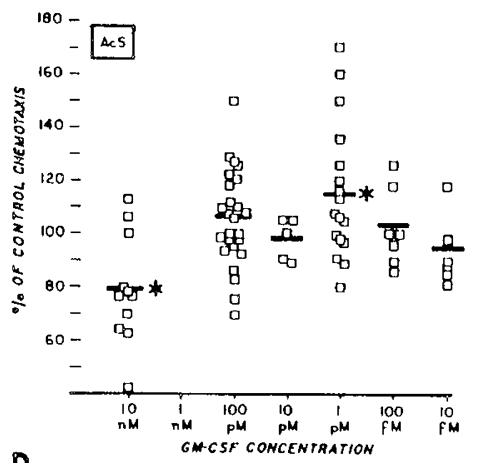

D.

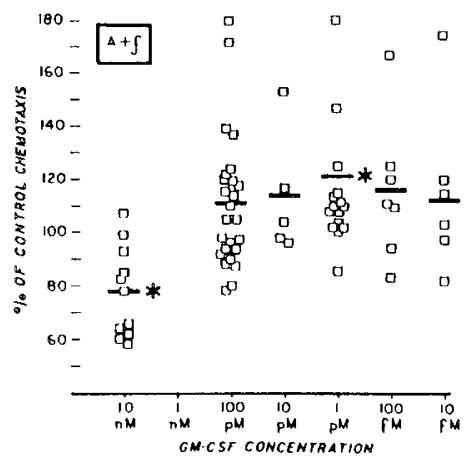

Fig. 1. The effects of rhGM-CSF on cord blood granulocyte locomotion. In each panel the locomotive stimulus is identified in the upper left corner. The vertical axis represents movement of granulocytes exposed to rhGM-CSF divided by the movement of the same population of granulocytes that had not been exposed to rhGM-CSF. Values of more than 100 reflect enhanced chemotaxis by rhGM-CSF treated cells whereas values less than 100 reflect suppression. At each concentration, squares represent the results of individual cord blood samples, each sample only being used once at a given concentration of rhGM-CSF. Bars show the mean locomotion of the individual experiments at each concentration of rhGM-CSF tested. Asterisk denotes $p<0.05$ as determined by paired sample $t$-test.

to the chemoattractant but the results were not statistically different from controls.

Figure 2 depicts the results of a representative image analysis experiment. The unshaded area represents the enhanced number of granulocytes responding to each chemoattractant after incubation with 1 pM rhGM-CSF.

Despite the enhancement of locomotive responses, exposure of cord blood granulocytes to $1 \mathrm{pM}$ rhGM-CSF did not normalize their locomotive responses to those observed in adult granulocytes (Table 1).

Effects of rhGM-CSF on granulocyte superoxide production. rhGM-CSF was not a stimulus for superoxide production by either adult or cord blood granulocytes $(0.0$ vs $0.2 \mathrm{nmol}$ superoxide, adult granulocytes $\pm 100 \mathrm{pM}$ rhGM-CSF exposure $(n=$ 4) and 0.1 vs $0.5 \mathrm{nmol}$ superoxide, cord blood granulocytes \pm $100 \mathrm{pM}$ rhGM-CSF $(n=5)$. Incubation of cord blood granulocytes with $100 \mathrm{pM}$ rhGM-CSF for 30 and $60 \mathrm{~min}$ before fMLP stimulation significantly enhanced superoxide production by these cells ( $30 \mathrm{~min}, 157 \pm 8.5 \%$ of unexposed cells $(n=8) ; 60$ min $167 \pm 14.3 \%$ of unexposed cells $(n=8), p<0.01$ and $p<$ 0.01 , respectively). This enhancing effect was lost with longer incubation periods (Table 2). The total concentration of $100 \mathrm{pM}$ rhGM-CSF also significantly enhanced superoxide generation by adult granulocytes but only after a 60 -min exposure. Unlike cord blood cells, significantly increased superoxide production persisted after a 120-min incubation with rhGM-CSF (60 min: 152 $\pm 10 \%$ of unexposed cells $(n=5) ; 120$ min: $123 \pm 8 \%$ of unexposed cells $(n=5) ; p<0.02$ and $p<0.02$, respectively). Superoxide generation by cord blood granulocytes unexposed to rhGM-CSF was greater than unexposed adult cells, with a further increase after exposure to rhGM-CSF.

Effects of $r h G M-C S F$ on granulocyte membrane depolarization responses. In three to six experiments, cord blood granulocyte membrane depolarization responses were equivalent to those observed in paired adult control granulocytes for all fMLP concentrations tested $\left(10^{-6}\right.$ to $\left.10^{-8} \mathrm{M}\right)$. Exposure of either cord blood granulocytes or adult control granulocytes to $100 \mathrm{pM}$ GM-CSF for 30,60 , or 120 min before fMLP stimulation did not alter the membrane depolarization responses of either cell type.

Effects of rhGM-CSF on granulocyte phagocytosis. Phagocytosis of $S$. aureus by cord blood granulocytes was equivalent to that of adult granulocytes (Fig. 3). Preincubation $(30 \mathrm{~min})$ of cord blood cells with $100 \mathrm{pM}$ rhGM-CSF did not alter the numbers of granulocytes ingesting serum opsonized $S$. aureus.

Effects of rhGM-CSF on granulocyte bactericidal activity. Cord blood granulocyte bactericidal activity was equivalent to adult cell bactericidal activity (Table 3). Over a 5 log range of rhGMCSF concentrations (10 nM-1 pM), no alterations in bacterial killing by cord blood granulocytes were observed.

\section{DISCUSSION}

Overwhelming sepsis and meningitis occurs in one to three infants $/ 1000$ live births and in up to $30 \%$ of premature infants (28). Mortality in this disease varies from 20 to $50 \%$. The neonate's increased susceptibility to infection has been attributed to a number of abnormalities in its host defenses (11), including abnormalities in neonatal granulocyte function. Depressed locomotion toward chemoattractants (14-17), defective membrane depolarization responses compared to adult granulocytes (18), abnormal phagocytosis $(29,30)$, and depressed bactericidal activity (30) are among the abnormalities described. Oxygen metabolism is generally normal $(31,32)$, although stressed neonates have been reported to have diminished production of superoxide 


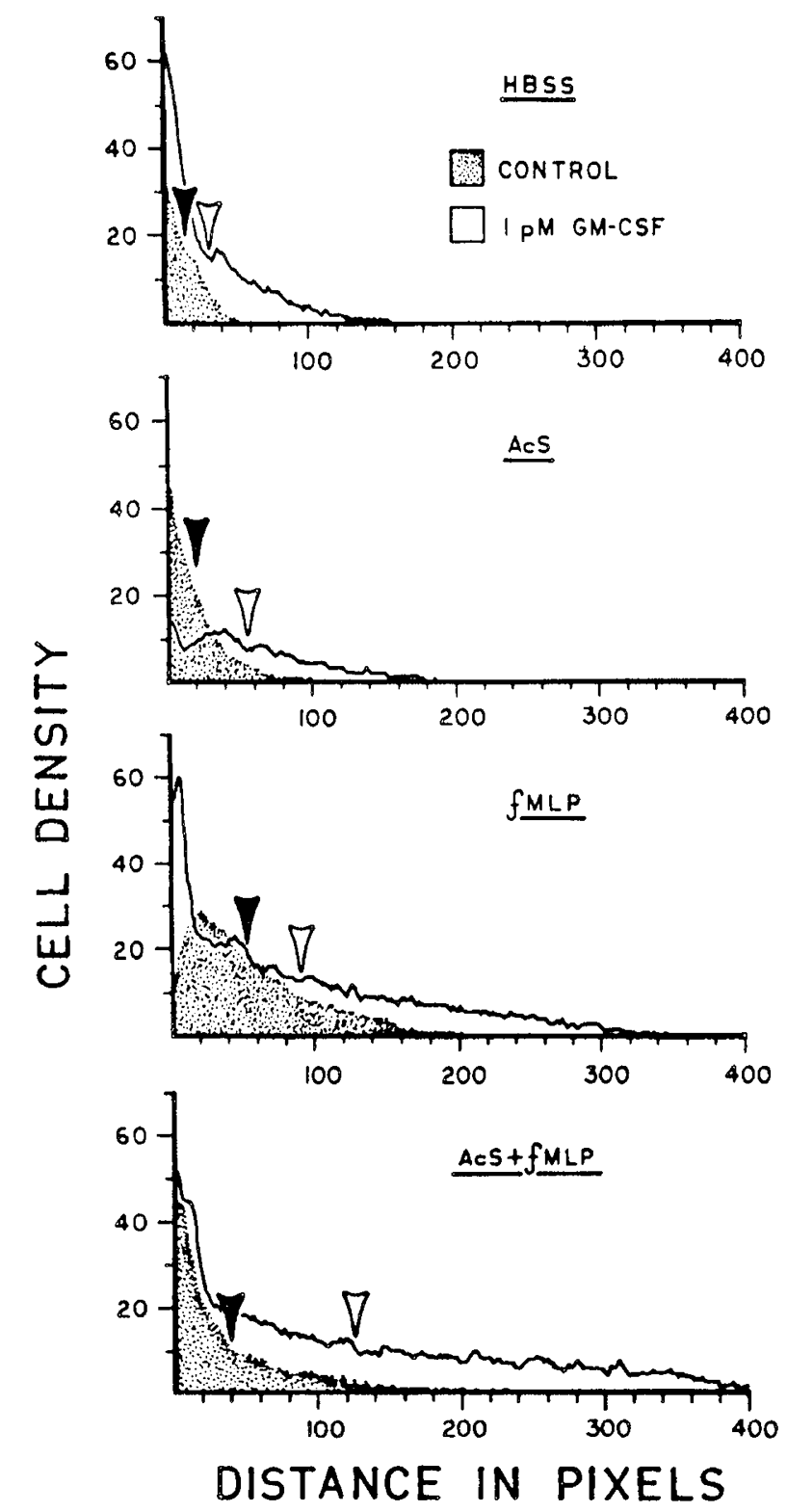

Fig. 2. Representative image analysis results examining cord blood granulocyte locomotion. The horizontal axis shows the distance moved by granulocytes toward the stimulus identified at upper right of each panel. One pixel $=6 \mu$. The vertical axis shows the density of cells at each pixel of distance. Arrows show mean distance migrated for control (closed arrow) and 1 pM GM-CSF exposed (open arrow) cord blood granulocytes. anion (32). rhGM-CSF in vitro has been reported to enhance each of these functions in granulocytes from adults.

We found that in vitro exposure to rhGM-CSF enhanced cord blood granulocyte locomotion and superoxide generation but did not effect the other functions tested. One picomolar rhGMCSF significantly enhanced leading front migration of cord blood granulocytes when either IMLP, activated serum or fMLP plus activated serum was used as a chemoattractant. This effect was not observed with adult granulocytes tested in the same chemotaxis assay system with in vitro exposure to the same rhGM-CSF (33).

Our data suggest that the effect of rhGM-CSF on cord blood granulocyte locomotion is complex. Multiple facets are altered depending on the concentration and mode of presentation of rhGM-CSF to the cell. As shown in this report and by others (10), rhGM-CSF is a weak chemoattractant; when presented in a non-gradient fashion, it should cause chemokinesis. We hypothesize that the enhancing effect on unstimulated locomotion seen at the $100 \mathrm{pM}$ rhGM-CSF concentration is such a chemokinetic effect. Inasmuch as the direct chemoattractant/chemokinetic activity of rhGM-CSF is weak, the chemokinetic effect is obscured when stronger chemoattractants (such as fMLP) are presented as a gradient, resulting in chemotaxis. At high concentrations (10 nM), rhGM-CSF suppresses chemotaxis, consistent with its original designation as neutrophil migration inhibition factor from T cells (9). Suppression of adult PMN chemotactic locomotion in vitro has also been observed at this rhGM-CSF concentration (33). At low GM-CSF concentrations (1 pM), an enhancing effect on cord granulocyte chemotactic locomotion occurs. Thus, rhGM-CSF can mediate a variety of locomotive effects on cord blood granulocytes, depending on the concentration and mode of presentation of the hematopoietin. Similar dose-dependent, opposing effects on neonatal granulocyte locomotion have been reported with pentoxifylline (34), a methylxan-

Table 2. Effects of rh GM-CSF on granulocyte superoxide production

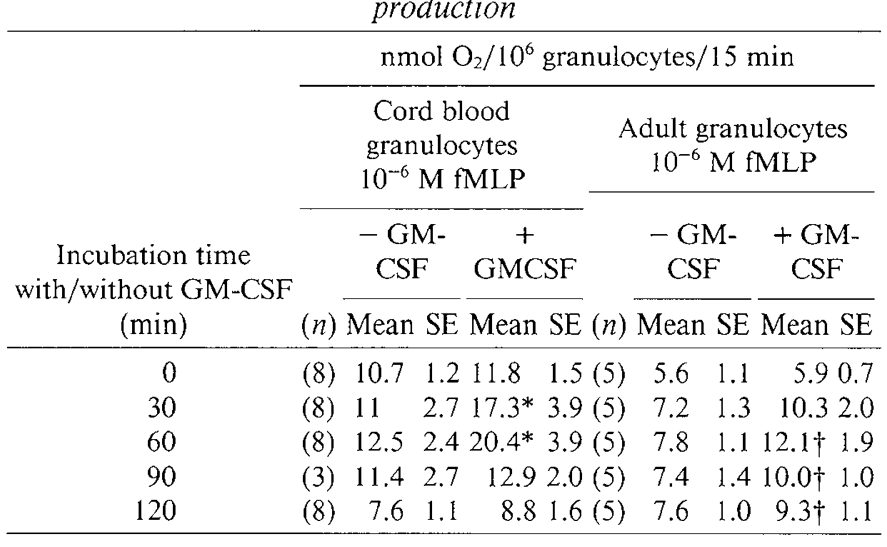

$* p<0.01$.

$\dagger p<0.02$.

Table 1. Effects of recombinant human GM-CSF on polymorphonuclear leukocyte locomotion*

\begin{tabular}{|c|c|c|c|c|c|c|c|}
\hline \multirow{2}{*}{$\begin{array}{l}\text { Locomotive } \\
\text { stimulus }\end{array}$} & \multicolumn{3}{|c|}{$\begin{array}{c}\text { Cord PMN movement } \\
\text { Adult PMN movement } \\
100\end{array}$} & \multicolumn{4}{|c|}{$\begin{array}{c}\text { Cord PMN }+1 \text { pM GM-CSF movement } \\
\text { Adult PMN movement } \\
100\end{array} \times$} \\
\hline & $(n)$ & Mean & SE & $(n)$ & Mean & SE & $p$ \\
\hline Hanks' balanced salt solution & (18) & 73 & 7 & $(18)$ & 84 & 9 & NS \\
\hline Activated serum & (18) & 80 & 10 & $(18)$ & 91 & 12 & $<0.025$ \\
\hline $\operatorname{fMLP}\left(5 \times 10^{-7} \mathrm{M}\right)$ & (18) & 68 & 6 & (18) & 80 & 8 & $<0.020$ \\
\hline Activated serum + fMLP $\left(5 \times 10^{-7} \mathrm{M}\right)$ & $(17)$ & 72 & 7 & $(17)$ & 84 & 7 & $<0.010$ \\
\hline
\end{tabular}

${ }^{*}$ Statistical significance determined by paired sample $t$-test. 


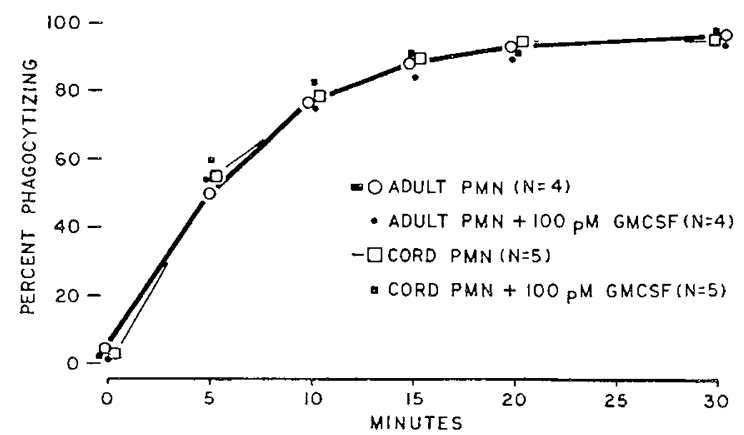

Fig. 3. The effect of rhGM-CSF on granulocyte phagocytosis of $S$. aureus. The vertical axis shows the percentage of granulocytes with one or more intracellular bacteria. The horizontal axis shows the duration of contact with $S$. aureus before exposure to lysostaphin. Each curve is the mean of four to five experiments.

Table 3. Effects of rhGM-CSF on granulocyte bactericidal activity*

\begin{tabular}{|c|c|c|c|c|c|c|}
\hline \multirow[b]{3}{*}{ Condition } & \multicolumn{6}{|c|}{$\%$ bacterial survival } \\
\hline & \multicolumn{2}{|c|}{$20 \mathrm{~min}$} & \multicolumn{2}{|c|}{$45 \mathrm{~min}$} & \multicolumn{2}{|c|}{$90 \mathrm{~min}$} \\
\hline & Mean & SE & Mean & $\mathrm{SE}$ & Mean & $\mathrm{SE}$ \\
\hline Adult cells & 51 & 4 & 32 & 6 & 17 & 1 \\
\hline Cord Blood cells & 56 & 3 & 39 & 8 & 17 & 6 \\
\hline Cord Blood cells + 10 nM GM-CSF & 61 & 5 & 35 & 10 & 19 & 3 \\
\hline Cord Blood cells +100 pM GM-CSF & 55 & 9 & 36 & 9 & 17 & 5 \\
\hline Cord Blood cells + 1 pM GM-CSF & 56 & 8 & 36 & 7 & 17 & 6 \\
\hline
\end{tabular}

* Data shown are from three separate experiments using a granulocyte: bacteria ratio of $1: 2$.

thine drug capable of enhancing human cord blood granulocyte chemotaxis (35).

The distance moved by the leading front of granulocytes is typically the only parameter measured in an under agarose chemotaxis assay, a parameter that could be enhanced by increased locomotion of only a small subpopulation of cells. To determine if rhGM-CSF enhanced chemotaxis by effecting a subpopulation of cells or the whole cell population, we used an image analysis system to specifically examine the effects of rhGM-CSF exposure on two other parameters of locomotion: the mean distance migrated by the cell population and the area under the population distribution (which represents the numbers of cells responding to the stimulus). In the three experiments examined, when fMLP was the chemoattractant, 1 pM rhGMCSF significantly enhanced both of these parameters, in addition to the leading front distance. It appears unlikely, then, that the observed effects of the hematopoietin are due only to stimulation or suppression of a small subpopulation of responsive cells. Although rhGM-CSF did not normalize the locomotion of cord blood granulocytes when compared to adult cells, these experiments do confirm that the locomotive defect present in cord blood granulocytes can be partially reversed by pharmacologic means, a fact only recently appreciated (35).

Superoxide anion generation by cord blood granulocytes was increased after exposure to $100 \mathrm{pM}$ rhGM-CSF, as has been previously reported for adult granulocytes (6). Cord blood cells exhibited maximal stimulation after a 30 - to 60-minute incubation with rhGM-CSF but no alteration in superoxide anion production compared to untreated cord cells after a 2-h incubation. In our study, adult granulocytes also demonstrated an increase in superoxide anion production after incubation with rhGM-CSF, confirming the previous work. However, we showed the effect of rhGM-CSF on adult cells was maximal after $60 \mathrm{~min}$ as opposed to the 120 min reported by others (6). The reason for the time discrepancy between studies is unclear.
Cord blood and adult granulocyte phagocytosis, bactericidal activity and membrane depolarization responses were unchanged after exposure to rhGM-CSF. Other reports $(6,36)$ have reported increased phagocytosis after rhGM-CSF exposure. In their experiments, preopsonized organisms or low concentrations of serum were used to demonstrate the enhancing effect. The use of $10 \%$ autologous serum in our assay system may have obscured small degrees of enhancement. We conclude that if GM-CSF does enhance phagocytosis and bactericidal activity, it is a minor effect under optimal conditions for phagocytosis and microbial killing. Cord granulocyte membrane depolarization, a function thought to possibly reflect receptor-ligand initiated signal transduction in the granulocyte, has previously been reported to be defective in neonatal cells (18). Using fMLP as the stimulus, we found that neonatal and adult granulocytes had equivalent responses and that rhGM-CSF did not affect these responses in either cell type.

Several mechanisms have been proposed to explain selected in vitro effects of rhGM-CSF on granulocytes. Weisbart et al. (37) suggest that certain effects are mediated through changes in the affinity state of fMLP receptors. High affinity fMLP receptors are related to enhanced chemotaxis whereas low affinity receptors appear to be associated with increased oxidative metabolism (38). These authors noted that after brief exposure to rhGM$\mathrm{CSF}$, adult granulocytes showed a rapid increase in high affinity receptors which temporally coincided with enhancement of chemotaxis by rhGM-CSF. Longer incubation was associated with a shift to low affinity receptors, and temporally coincided with enhancement of granulocyte oxygen metabolism. Although our studies only examine neonatal cell function and not fMLP receptor affinities, our results, showing enhancement of neonatal cell locomotion, are at least partially consistent with this hypothesis.

A second mechanism postulates that rhGM-CSF recruits a subpopulation of granulocytes that are unresponsive to fMLP before exposure to GM-CSF (39). Subpopulations of neonatal cells with different functional capacities have previously been demonstrated (40). Our results could be consistent with the recruitment of a large population of poorly responsive cord blood granulocytes into the fMLP responsive population. Further testing of this hypothesis is currently underway.

In conclusion, we have demonstrated that selected cord blood granulocyte functions are enhanced by in vitro exposure to rhGM-CSF. An animal model is currently being developed to determine the in vivo significance of these in vitro observations.

Acknowledgments. The authors thank Sarah Mcllheran for her technical expertise and Anne Wright for her excellent word processing.

\section{REFERENCES}

1. Metcalf D 1984 The granulocyte-macrophage colony-stimulating factors. Science 229:16-22

2. Sachs L 1987 The molecular control of blood cell development. Science 238:1374-1378

3. Clark SC, Kamen R 1987 The human hematopoietic colony-stimulating factors. Science 236:1229-1237

4. Burgess AW, Begley CG, Johnson GR, Lopez AF, Williamson DJ, Mermod JJ, Simpson RJ, Schmitz A, Delmarter JF 1987 Purification and properties of bacterially synthesized human granulocyte-macrophage colony-stimulating factor. Blood 69:43-51

5. Fleischmann J, Golde DW, Weisbart RH, Gasson JC 1986 Granulocytemacrophage colony-stimulating factor enhances phagocytosis of bacteria by human neutrophils. Blood 68:708-711

6. Weisbart RH, Kwan L, Golde DW, Gasson JC 1987 Human GM-CSF primes neutrophils for enhanced oxidative metabolism in response to the major physiological chemoattractants. Blood $69: 18-21$

7. Sullivan R, Griffin JD, Simons ER, Schafer AI, Meshulam T, Fredette JP, Maas AK, Gadenne AS, Leavitt JL, Melnick DA 1987 Effects of recombinant human granulocyte and macrophage colony-stimulating factors on signal transduction pathways in human granulocytes. J. Immunol 139:3422-3430 
8. Arnaout MA, Wang EA, Clark SC, Sieff CA 1986 Human recombinant granulocyte-macrophage colony-stimulating factor increases cell-to-cell adhesion and surface glycoproteins on mature granulocytes. J Clin Invest 78:597-601

9. Gasson JC, Weisbart RH, Kaufman SE, Clark SC, Golde DW 1984 Purified human granulocyte-macrophage colony-stimulating factor: direct action on neutrophils. Science 226:1339-1342

10. Wang JM, Colella S, Allavena P, Montovani A 1987 Chemotactic activity of human recombinant granulocyte-macrophage colony stimulating factor. Immunology 60:439-444

11. Wilson CB 1986 Immunologic basis for increased susceptibility of the neonate to infection. J Pediatr 108:1-12

12. Hill HR 1987 Biochemical, structural, and functional abnormalities of polymorphonuclear leukocytes in the neonate. Pediatr Res 22:375-382

13. Ambruso DR, Altenburger KM, Johnston RB 1979 Defective oxidative metabolism in newborn neutrophils: discrepancy between superoxide anion and hydroxyl radical generation. Pediatrics 64:722-725

14. Christensen RD, Rothstein G 1980 Efficiency of neutrophil migration in the neonate. Pediatr Res 14:1147-1149

15. Anderson DC, Hughes BJ, Wible LJ, Perry GJ, Smith CW, Brinkley BR 1984 Impaired motility of neonatal PMN Leukocytes: relationship to abnormalities of cell orientation and assembly of microtubules in chemotactic gradients. J Leuk Biol 36:1-15

16. Yegin O 1983 Chemotaxis in childhood. Pediatr Res 17:183-187

17. Krause PJ, Herson VC, Bontin-Lebowitz J, Eisenfeld L, Block C, LoBello T, Maderazo E 1986 Polymorphonuclear leukocyte adherence and chemotaxis in stressed and healthy neonates. Pediatr Res 20:296-300

18. Sacchi F, Hill HR 1984 Defective membrane potential changes in neutrophils from human neonates. J Exp Med 160:1247-1251

19. Chirico G, Marconi M, DeAmici M, Gasparoni A, Mingrat G, Chiara A, Rondini G, Ugazio AG 1985 Deficiency of neutrophil bactericidal activity in term and pre-term infants. Biol Neonate 47:125-129

20. Boyum A 1968 Isolation of mononuclear cells and granulocytes from human peripheral blood. Scand J Clin Lab 21(suppl 97):77-89

21. Cantrell MA, Anderson D, Cerretii DP, Price VL, McKereghan K, Tushinski RJ, Mochozuki DY, Larsen A, Grabstein K, Gillis S, Cooman D 1985 Cloning, sequence and expression of a human granulocyte-macrophage colony-stimulating factor. Proc Natl Acad Sci USA 82:6250-6254

22. Grabstein KH, Urdal DL, Tushinski RJ, Mochizuki DY, Price VL, Cantrell MA, Gillis S, Conlon PJ 1986 Induction of macrophage tumorcidal activity by granulocyte-macrophage colony-stimulating factor. Science 232:506-508

23. Nelson RD, McCormack RT, Fiegel VD 1970 Chemotaxis of human leukocytes under agarose. In: Gallin JT, Quie PG (eds) Leukocyte Chemotaxis: Methods, Physiology and Clinical Implications. Raven Press, New York, pp $25-42$

24. Johnson DA, Moffitt M, Tang K 1986 An Interactive General Purpose Image Digitalizing System, 4th ed. Department of Biomath, M.D. Anderson Hos- pital and Tumor Institute, Houston, TX

25. Margoliash E, Frohwirt N 1959 Spectrum of horseheart cytochrome c. Biochem J 71:570-572

26. Seligmann BE, Gallin EK, Martin DL, Shain W, Gallin JI 1980 Interaction of chemotactic factors with human polymorphonuclear leukocytes. Studies using a membrane potential-sensitive cyanine dye. J Memb Biol 52:257-272

27. Tan JS, Watanakunakorn C, Phair JP 1971 A modified assay of neutrophil function: Use of lysostaphin to differentiate defective phagocytosis from impaired intracellular killing. J Lab Clin Invest Med 78:316-322

28. Siegel JD, McCracken GH 1981 Sepsis neonatorum. N Engl J Med 304:643647

29. Miller ME 1979 Phagocytic function in the neonate: selected aspects. Pediatrics 64:709-712

30. Wright WC, Ank BJ, Hebert J, Stichn ER 1975 Decreased bactericidal activity of leukocytes of stressed newborn infants. Pediatrics 56:579-584

31. Newburger PW 1982 Superoxide generation by human fetal granulocytes. Pediatr Res 16:373-376

32. Shigeoka AO, Charette RP, Wyman ML, Hill HR 1981 Defective oxidative responses of neutrophils from stressed neonates. J Pediatr 93:392-398

33. Buescher ES, McIlheran SM, Vadhan-Raj S 1988 Effects of in vivo administration of recombinant human granulocyte-macrophage colony-stimulating factor on human neutrophil chemotaxis and oxygen metabolism. $J$ Infect Dis 158:1140-1142

34. Krause PJ, Kristie J, Wang W-P, Eisenfeld L, Herson VC, Maderazo EG, Jozaki J, Kreutzer DL 1987 Pentoxifylline enhancement of defective neutrophil function and host defense in neonatal mice. Am J Pathol 129:217-222

35. Hill HR, Augustine NH, Newton JA, Shigeoka AO, Morris E, Sacchi F 1987 Correction of a development defect in neutrophil activation and movement. Am J Pathol 128:307-314

36. Lopez AF, Williamson DJ, Gamble JR, Begley CG, Harian JM, Klebanoff SJ, Wattersdorph A, Wong G, Clark SC, Vadas MA 1986 Recombinant human granulocyte-macrophage colony-stimulating factor stimulates in vitro mature human neutrophil and eosinophil function, surface receptor expression, and survival. J Clin Invest 78:1220-1228

37. Weisbart RH, Golde DW, Gasson JC 1986 Biosynthetic human GM-CSF modulates the number and affinity of neutrophil f-met-leu-phe receptors. $J$ Immunol 137:3584-3587

38. Showell HJ, Freer RJ, Zigmond SH, Shiffmann E, Aswanikumer S, Corcoran $\mathrm{B}$, Becker E 1976 The structure-activity relations of synthetic peptides as chemotactic factors and inducers of lysosomal enzyme secretion for neutrophils. J Exp Med 143:1154-1169.

39. Fletcher MP, Gasson JC 1988 Enhancement of neutrophil function by granulocyte-macrophage colony-stimulating factor involves recruitment of a less responsive subpopulation. Blood 71:652-658

40. Krause PJ, Malech HL, Kristie J, Kosciol CM, Herson VC, Eisenfeld L, Pastuszak WT, Kraus A, Seligmann B 1986 Polymorphonuclear leukocyte heterogeneity in neonates and adults. Blood 68:200-204 